\title{
Comparative Study of Smokers, Ex-Smokers, and Nonsmokers who Have Experienced Myocardial Infarction
}

\author{
Diogo Nozawa, Roberto Alexandre Franken, Karina de Cássia Braga Ribeiro, Afonso Celso Pereira, \\ Sandra Regina Schwarzwälder Sprovieri, Valdir Golin
}

São Paulo, SP - Brazil

\begin{abstract}
Objective - To assess the impact of smoking on in-hospital morbidity and mortality in patients who have experienced acute myocardial infarction and to assess the association between smoking and other cardiovascular risk factors and clinical data.
\end{abstract}

Methods - A prospective cohort study analyzed 121 patients, including 54 smokers, 35 ex-smokers, and 32 nonsmokers.

Results - Using the chi-square test $(P<0.05)$, an association between smoking and the risk factors sex, age, and diabetes was documented. Among the morbidity and mortality variables, only acute pulmonary edema showed a statistically significant difference $(O R=9.5 ; 95 \% C I)$, which was greater in the ex-smoker group than in the nonsmoker group.

Conclusion - An association between smoking and some cardiovascular riskfactors was observed, but no statistical difference in morbidity and mortality was observed in the groups studied, except for the variable acute pulmonary edema.

Key words: smoking, myocardial infarction

Santa Casa de Misericórdia de São Paulo

Mailing address: Roberto A. Franken - Rua Dr. Franco da Rocha, 163/52

Cep 05015-040 - São Paulo, SP, Brazil - E-mail: franken@terra.com.br

English version by Stela Maris C. e Gandour

Received: 04/30/02

Accepted: 05/13/03
Smoking has been associated with an increase in morbidity and mortality due to atherosclerotic coronary artery disease, which has been confirmed in several studies ${ }^{1-9}$. This association results from the multiple noxious effects of smoking on the mechanisms of atherogenesis and thrombosis, and in the vasomotor and arrhythmogenic mechanisms ${ }^{1}$.

Several studies have shown that smoking, at the time of acute myocardial infarction, is not a risk factor for subsequent death ${ }^{1-5}$. Smokers have a better in-hospital clinical evolution independent of thrombolytic therapy ${ }^{1,2}$, and some studies ${ }^{3,5-8}$ have reported that smokers tend to have a better prognosis. Surprisingly, smoking has even appeared as a factor of better prognosis after the event ${ }^{5}$.

Some multicenter studies, however, have emphasized that after adjusting for age and other variables, no statistical difference exists in the in-hospital and out-of-hospital prognosis between smokers and nonsmokers ${ }^{2,5-8}$.

This study aimed at assessing the impact of smoking on in-hospital morbidity and mortality of patients experiencing acute myocardial infarction and to assess the association of smoking with other cardiovascular risk factors and clinical data.

\section{Methods}

A prospective cohort study was carried out with 121 patients diagnosed with acute myocardial infarction, who were referred to the Central Emergency Unit of the Santa Casa de Misericórdia of São Paulo from January 1999 to June 2000. Their diagnosis was based on clinical and electrocardiographic criteria and on the elevation of cardiac enzymes (MB fraction of creatine phosphokinase) ${ }^{9}$, which were followed up during the entire length of hospitalization.

The patients were divided into 3 groups as follows: smokers, ex-smokers, and nonsmokers. Smokers were the patients who smoked regularly for at least 1 year before the myocardial infarction; ex-smokers were those who smoked regularly but interrupted their habit at least 1 year before the infarction; nonsmokers never smoked.

Each patient was interviewed so that the risk profile of 
cardiovascular diseases could be determined. The following data were assessed: age, sex, and personal antecedents, such as systemic arterial hypertension, diabetes mellitus, alcoholism, dyslipidemia, angina pectoris, hyperuricemia, obesity, sedentary life style, and previous myocardial infarction.

On the patients' admission, their clinical conditions were assessed using the variables time to reach the service and Killip classification on admission. The patients were reclassified after 24 hours (Killip).

Assessment of morbidity and mortality in each group was based on data for each patient: in-hospital complications - arrhythmias, acute pulmonary edema, cardiogenic shock, stroke, reinfarction, pulmonary thromboembolism, deep venous thrombosis, and death.

The chi-square test was used for assessing the association of smoking with other risk factors, time to reach the hospital, Killip on hospital admission, and use of a thrombolytic agent. Analyzing the risk factors for morbidity and mortality (death, arrhythmias, shock, and others), the odds ratio for each variable studied and the respective confidence intervals were calculated. The statistical significance level adopted was $5 \%$ for all tests.

\section{Results}

The study assessed 121 patients, 54 (44.6\%) smokers, $32(26.4 \%)$ ex-smokers and 35 (29\%) nonsmokers. Three patients were excluded from the study because they died immediately after entering the hospital.

A statistically significant association was observed between smoking and $\operatorname{sex}(\mathrm{P}=0.001)$, alcoholism $(\mathrm{P}=0.03)$, diabetes $(\mathrm{P}=0.02)$, and age $(\mathrm{P}=0.01)$. No statistically significant associations were found between smoking and the other risk factors studied (tab. I).

A significant increase in the risk of acute pulmonary edema was observed in the ex-smokers as compared with that in the nonsmokers $(\mathrm{OR}=9.5 ; 95 \% \mathrm{CI})$.

The smokers showed a reduction in the risk of death, shock, infection. This reduction, however, was not statistically significant for any event. On the other hand, an increase in the risk of ventricular fibrillation/ventricular tachycardia, hypotension, and acute pulmonary edema was observed, but also with no statistical significance (tab. II).

A reduction in the risk of death, shock, and infection was also observed, but with no statistical significance for the ex-smokers. In this group, an increase in the risk of ventricular fibrillation/ventricular tachycardia and congestive heart failure was observed, but with no statistical significance (tab. II).

\section{Discussion}

Several hypotheses have already been formulated to explain the paradox of better prognosis in the group of smokers. Smokers experience acute myocardial infarction at a younger age and, therefore, have a more benign risk profi-

\begin{tabular}{|c|c|c|c|c|c|}
\hline Variable & Category & Nonsmoker & Smoker & Ex-smoker & $\mathrm{P}$ \\
\hline \multirow[t]{2}{*}{ Sex } & Male & 18.8 & 49.4 & 31.8 & $0.001 *$ \\
\hline & Female & 52.8 & 33.3 & 13.9 & \\
\hline \multirow[t]{2}{*}{ Alcoholism } & No & 35.3 & 37.6 & 27.1 & $0.03 *$ \\
\hline & Yes & 13.9 & 61.0 & 25.0 & \\
\hline \multirow[t]{2}{*}{ Hypertension } & No & 20.8 & 50.0 & 29.2 & 0.28 \\
\hline & Yes & 34.2 & 41.1 & 24.7 & \\
\hline \multirow[t]{2}{*}{ Diabetes } & No & 24.5 & 51.1 & 24.5 & $0.02 *$ \\
\hline & Yes & 44.4 & 22.2 & 33.3 & \\
\hline \multirow{2}{*}{ Obesity } & No & 25.0 & 51.3 & 23.8 & 0.12 \\
\hline & Yes & 36.6 & 31.7 & 31.7 & \\
\hline \multirow{2}{*}{ Angina } & No & 27.0 & 42.9 & 30.2 & 0.62 \\
\hline & Yes & 31.0 & 46.6 & 22.4 & \\
\hline Sedentary & No & 16.1 & 51.6 & 32.3 & 0.18 \\
\hline lifestyle & Yes & 33.3 & 42.2 & 24.4 & \\
\hline \multirow[t]{2}{*}{ Dyslipidemia } & No & 28.1 & 47.1 & 24.7 & 0.69 \\
\hline & Yes & 30.6 & 38.9 & 30.6 & \\
\hline \multirow[t]{2}{*}{ Uric acid } & No & 29.5 & 45.5 & 25.0 & 0.44 \\
\hline & Yes & 22.2 & 33.3 & 44.0 & \\
\hline \multirow[t]{2}{*}{ Killip } & I/II & 30.4 & 43.8 & 25.9 & 0.47 \\
\hline & III/IV & 11.1 & 55.6 & 33.3 & \\
\hline Time to & 0 to $6 \mathrm{~h}$ & 24.4 & 50.0 & 25.6 & 0.15 \\
\hline \multirow[t]{2}{*}{ admission } & 7 to $12 \mathrm{~h}$ & 52.9 & 23.5 & 23.5 & \\
\hline & More than $12 \mathrm{~h}$ & h $\quad 27.8$ & 38.9 & 33.3 & \\
\hline \multirow[t]{2}{*}{ Age } & $<70$ years & 25.3 & 51.6 & 23.2 & $0.01 *$ \\
\hline & $>70$ years & 42.3 & 19.2 & 38.5 & \\
\hline
\end{tabular}

le. In addition, acute myocardial infarction is usually seen as the result of 2 pathogenic mechanisms (atherosclerosis and thrombosis), whose balance is altered by smoking. Due to the thrombogenic effect of cigarette smoking, smokers experiencing infarction may have a relatively smaller atherosclerotic lesion and more thrombi in the site of coronary occlusion, and, consequently, they may respond better to thrombolytic therapy ${ }^{1-3,5,7}$. Another apparent cause of this paradox is that a great proportion of smokers die prior to hospital admission. Yet, evidence exists that the sites of infarction differ between smokers and nonsmokers ${ }^{3,4}$.

In this study, smokers were younger than nonsmokers, which is in accordance with the findings of several published studies ${ }^{1-5}$. The GISSI 2 Study (Gruppo Italiano per lo Studio della Sopravvivenza nell'Infarto Miocardico) reported that smokers were approximately 11 years younger than nonsmokers ${ }^{2}$, and the Israeli Thrombolytic National Survey (ITNS) reported that smokers were on average 10 years younger than nonsmokers ${ }^{5}$. These 2 studies also reported a greater frequency of female patients among nonsmokers, which was also observed in our study. In addition, smoking was not significantly associated with the variables death, shock and infection.

Another factor emphasized in the literature is that patient's admission to the hospital within 6 hours or less from symptom onset was more common among smokers. One may assume that smokers are more prepared or aware of the symptoms of acute coronary heart disease. In our study, the proportion of patients entering the emergency unit within 6 


\begin{tabular}{|c|c|c|c|c|c|c|c|c|c|}
\hline Event & Nonsmoker (\%) & OR & $95 \% \mathrm{CI}$ & Smoker $(\%)$ & OR & $95 \% \mathrm{CI}$ & Ex-smoker $(\%)$ & OR & $95 \% \mathrm{CI}$ \\
\hline Death & 14.3 & 1.00 & - & 7.4 & 0.48 & $0.12-1.92$ & 12.50 & 0.85 & $0.21-3.52$ \\
\hline Shock & 20.0 & 1.00 & - & 13.0 & 0.59 & $0.19-1.87$ & 15.60 & 0.74 & $0.2-2.60$ \\
\hline VF/VT & 8.6 & 1.00 & - & 22.2 & 3.00 & $0.79-11.70$ & 9.40 & 1.10 & $0.2-5.90$ \\
\hline Infection & 20.0 & 1.00 & - & 9.3 & 0.40 & $0.12-1.41$ & 15.60 & 0.74 & $0.21-2.60$ \\
\hline Hypotension & 2.9 & 1.00 & - & 11.1 & 4.20 & $0.49-36.9$ & 0.00 & - & - \\
\hline PE & 2.9 & 1.00 & - & 11.1 & 4.20 & $0.49-36.9$ & 21.90 & 9.50 & $1.10-82.3$ \\
\hline
\end{tabular}

hours after symptom onset was greater in the group of smokers, but with no statistical significance.

No statistically significant association was observed between smoking and the various risk factors for acute myocardial infarction, such as hypertension, obesity, angina, sedentary lifestyle, dyslipidemia, and uric acid. Only diabetes and alcoholism were associated with smoking. Although not significantly, smokers usually have a more benign risk profile than do nonsmokers and ex-smokers, and this has also been reported in other studies ${ }^{1,2,4,5,7}$.

In the literature, a greater incidence of ventricular fibrillation and tachycardia has been reported in smokers, while a greater incidence of death and other complications (cardiogenic shock, infections, severe mitral regurgitation, atrial fibrillation) has been reported in nonsmokers ${ }^{2,5}$. Smoking increased the risk of ventricular fibrillation/ventricular tachycardia and hypotension, but with no statistical significance. A greater risk of cardiogenic shock, infections, and death was observed in nonsmokers, but with no statistical significance ${ }^{2,5}$. The ITNS and the GISSI-2 studies assessed, respectively, 999 and 9720 patients.

Like smokers, ex-smokers were younger and predomi- nantly males. In regard to the other risk factors studied, the groups had similar percentages. Therefore, we could assume that ex-smokers would have a similar probability of experiencing a cardiovascular event if they had not smoked. Smoking might have accelerated the atherosclerotic disease, causing ex-smokers to experience acute myocardial infarction at a younger age than nonsmokers.

In regard to the time elapsed between symptom onset and arrival at the hospital, ex-smokers had percentages closer to those of smokers, which could be a cause for their better prognosis as compared with that of nonsmokers.

Acute pulmonary edema was the most surprising variable, with, in disagreement with the literature, the greatest statistically significant risk in ex-smokers. Coincidentally, the patients studied may have had some type of previous ventricular dysfunction, which could help to explain the lack of statistical significance in the complications between both groups

In conclusion, in our study, an association between smoking and some cardiovascular risk factors was observed. However, no statistical difference in morbidity and mortality was observed between the groups studied, except in the variable acute pulmonary edema.

\section{References}

1. Sahger D, Cercek B, Cannon CP, et al. How do smokers differ from non smokers in their response to trombolisis (The TIMI-4 trial). Am J Cardiol 1995; 75: 232-6.

2. Maggioni AP, Piantadosi F, Santoro E, Franzosi MG. Smoking is not a protective factor for patients with acute myocardial infarction: the viewpoint of the GISSI2 study. G Ital Cardiol 1998; 28: 970-8.

3. Molstad P. First myocardial infarction in smokers. Eur Heart J 1991; 12: 753-9.

4. Robinson K, Conroy RM, Mulcahy R. Smoking and acute coronary heart disease: a comparative study. Br Heart J 1988; 60: 465-9.

5. Gottlieb S, Bokyo V, Zahger D, Balkin J, Hod H, Pelled B, Stern S, Behar S for Israeli Thrombolytic Survey Group. J Am Coll Cardiol 1996; 28:1506-13.
6. Kannel WB. Update on the role of cigarrete smoking in coronary artery disease Am Heart J 1981; 101: 319-28

7. Gomez AM, Karagounis LA, Allen A, Anderson JL for the TEAM-2 Investigators. Effect of cigarrete smoking on coronary patency after thrombolytic therapy for myocardial infarction. Am J Cardiol 1993; 72:373-78.

8. Kelly TL, Gilpin E, Ahnve S, Henning H, Ross Jr J. Smoking status at the time of acute myocardial infarction and subsequent prognosis. Am Heart J 1975; 110 : 535-41.

9. Nicolau JC, César LAM, Luz PL, et al. Como diagnosticar e tratar o infarto agudo do miocárdio. Revista Brasileira de Medicina 1998; 55: 139-45. 